\title{
Tunneled peritoneal catheters for the palliative thera- py of malignant ascites
}

\author{
YVONNE RYAN ${ }^{1}$, KAREN LYONS ${ }^{2}$, JOHN HANSEN ${ }^{3}$, AISLING O'GORMAN ${ }^{4}$
}

\begin{abstract}
Objective: Malignant ascites presents difficult management issues in the palliative care population and results in distressing symptoms and recurrent hospital admissions. The palliative care services in Our Lady of Lourdes Hospital have been using radiologically guided tunneled peritoneal catheters for the palliative therapy of troublesome malignant ascites. We conducted a review of this management strategy.
\end{abstract}

Methods: There were 10 catheters inserted in 9 patients between May 2007 and June 2011 in patients with malignant ascites.

Results: There were no procedural related mortalities or major complications. Mean catheter life was 98.9 days. Post catheter re-hospitalization rate was 1.55 times per patient. Mean patient survival post insertion was 140 days. Eighty eight percent of patients achieved death at home.

Conclusion: We conclude that this is a safe and useful strategy in the management of malignant ascites in a palliative care population.

Keywords: Tunneled peritoneal catheter, Palliative therapy, Malignant ascites

\section{Introduction}

Malignant ascites is a common condition and can present difficult management issues in the palliative care population in their final months of life. Intractable ascites can result in distressing symptoms leading to recurrent hospital admissions. Many patients respond poorly to sodium restriction and diuretic therapy $[1,2]$ and attend the Accident and Emergency Department when they become symptomatic. They often require admission for repeated paracentesis which impacts significantly on the patients' quality of life in their final months.

There is currently no consensus on the optimal management of malignant ascites. There are several reports of the use of peritoneal catheters for the management of malignant ascites [3-5]. A review of indwelling peritoneal catheters in 2009 found that they are a safe and useful strategy for malignant ascites [6]. A Cochrane systematic review of management of ascites in gynaecological malignancy found no randomized data to support any one management strategy [7].

We report on a series of consecutive patients who were managed with radiologically guided tunneled peritoneal catheters for malignant ascites.

\section{Methods}

We conducted a retrospective review of patients who had a radiologically guided tunneled
1 North Eastern General Practice

Training Scheme

2 Department of Radiology, Beaumont Hospital, Dublin

3 Our Lady of Lourdes Hospital, Drogheda, Co. Louth

4 Our Lady of Lourdes Hospital, Drogheda, Co. Louth

CORRESPONDING AUTHOR: Yvonne Ryan

North Eastern General Practice Training Scheme

yvonneryanc@gmail.com

Funding: This research received no specific grant from any funding agency in the public, commercial, or not-for-profit sectors. 
peritoneal catheter inserted between May 2007 and June 2011 for malignant ascites. Data were collected by reviewing radiology records and the patients' medical records.

\section{Data collection}

We collected data on patient demographics, catheter survival, patient survival, any complications or manipulation of the catheter post-insertion, and rehospitalization. All patients had at least one prior paracentesis for symptomatic malignant ascites prior to consideration for catheter insertion.

\section{Catheter insertion}

The catheter used was a Cook Medical spiral chronic peritoneal dialysis catheter (Cook Incorporated Bloomington, In47404 USA). This is a silicone $16 \mathrm{fr}$ catheter with dual Dacron retention cuffs and a spiral tip configuration.

The decision to insert a catheter was made following discussion between the palliative care consultant caring for the patient and the radiologist. Informed consent was obtained from the patient. All catheters were inserted by the same consultant and radiologist. Periprocedural antibiotics were not given routinely. Patients were offered conscious sedation with Hypnoval $2 \mathrm{mg}$ and Fentanyl 50mcg IV. The procedure was well tolerated in all patients.

An initial ultrasound examination was performed to confirm the ascites and identify the pocket most appropriate for catheter placement. Under ultrasound guidance, the peritoneal cavity was punctured and access secured with a 0.035 guide wire. The subcutaneous tract was then fashioned. The initial puncture site represents the distal point of the tract. The proximal point is ten centimeters away from this site. The tract was infiltrated with local anesthetic and with a tunneling trocar. The catheter was advanced in the subcutaneous tissue from proximal to distal skin puncture site. Over the guidewire, the initial puncture site was serially dilated and a $16 \mathrm{fr}$ spiral peritoneal drainage catheter was placed. Both puncture sites were closed using a purse string suture.

\section{Catheter management}

Three liters of ascitic fluid was drained initially via the catheter at the time of insertion. Serial drainages were subsequently performed as and when the patients became symptomatic. Patients who opted to self-drain at home performed the drainages using a three way tap and drainage bag or by connecting a pre-evacuated container. In some cases the palliative home care team performed the drainages at home using the same technique. The frequency of drainages was dictated by the patients' symptoms. Some patients opted to have the drainages electively in the oncology day ward. These patients attended weekly or biweekly depending on symptoms. These drainages were performed in the day ward, draining up to 3 liters at a time, by the palliative care team. We did not routinely administer fluids or albumin post drainage.

\section{Catheter removal}

Using blunt dissection, the catheter was dissected along the subcutaneous tunnel. Once the dacron cuffs are dissected free, the catheter was pulled free. A pressure dressing was applied over the site.

\section{Results}

We identified 9 patients who had a tunneled catheter inserted in Our Lady of Lourdes Hospital in the study period. Sixty-seven percent of the patients were female. The mean age was 64.2 years (range 45-90 years). The patient characteristics are presented in Table 1. There were 10 catheters inserted in 9 patients over the study period. The mean number of conventional paracenteses prior to insertion of the tube was 1.75 (range 1-4). The mean patient survival post insertion of first catheter was 140 days (range 8-599 days) .

\section{Complications}

There were no procedure related mortalities. There were no major complications including peritonitis, viscus perforation or hemorrhage requiring transfusion. There were several minor complications as described below and summarized in Table 2.

One patient became hypotensive immediately after insertion. This was attributed to the fact that 3 liters had been drained from her tube after insertion. This was resolved with discontinuing fluid removal temporarily and intravenous fluid administration.

Two patients had a mild cellulitis around the exit site and were treated with oral flucloxacillin for seven days as outpatients.

Three patients leaked ascitic fluid from the tunnel exit site shortly after insertion. This was believed to be caused by the pressure of the large volume asci- 
Table 1. Age, sex and diagnosis of the participants with details of time from diagnosis of cancer to the insertion of a tunneled peritoneal catheter

\begin{tabular}{lllllll}
\hline & Age & Sex & Diagnosis & $\begin{array}{l}\text { Date Inserted } \\
\text { (day/month/year) }\end{array}$ & $\begin{array}{l}\text { Time from diagnosis to insertion } \\
\text { (months) }\end{array}$ & No. of prior conventional paracenteses \\
\hline Patient 1 & 60 & F & Ovarian carcinoma & $01 / 09 / 2008$ & 17 & 2 \\
\hline Patient 2 & 45 & M & Colorectal carcinoma & $05 / 05 / 2009$ & 1 & 4 \\
\hline Patient 3 & 63 & M & Colorectal carcinoma & $15 / 10 / 2009$ & 20 & 1 \\
\hline Patient 4 & 50 & M & Cholangiocarcinoma & $16 / 04 / 2010$ & 17 & 1 \\
\hline Patient 5 & 90 & F & Metastatic melanoma & $09 / 07 / 2010$ & 365 & 1 \\
\hline Patient 6 & 79 & F & Primary peritoneal serous carcinoma & $17 / 08 / 2010$ & 27 & 1 \\
\hline Patient 7 & 59 & F & Pancreatic carcinoma & $13 / 04 / 2011$ & 18 & 1 \\
\hline Patient 8 & 68 & F & Ovarian carcinoma & $20 / 06 / 2011$ & 23 & 3 \\
\hline Patient 9 & 64 & F & Lobular breast carcinoma & $29 / 08 / 2011$ & 33 & 1 \\
\hline & & & & Mean: 58 & Mean: 1.67 \\
\hline
\end{tabular}

Note: Number of prior conventional paracenteses refers to the absolute number of conventional (ie. needle) abdominal paracenteses performed prior to the insertion of the peritoneal catheter. The means are displayed at the end of the columns.

Table 2. Complications, catheter survival and patient survival after catheter insertion

\begin{tabular}{|c|c|c|c|c|}
\hline & Complications & Outcome of Complication & Catheter Life (days) & Patient Survival after insertion (days) \\
\hline Patient 1 & None & & 296 & 296 \\
\hline Patient 2 & $\begin{array}{l}\text { Catheter failed to drain due to loculated } \\
\text { ascites/tract infiltration }\end{array}$ & Catheter removed & 29 & 71 \\
\hline \multirow{2}{*}{ Patient 3} & \multirow{2}{*}{ Catheter displaced by patient } & \multirow{2}{*}{ Catheter replaced } & 176 & 599 \\
\hline & & & $192 *$ & $398 *$ \\
\hline \multirow[t]{2}{*}{ Patient 4} & Leak & Required increased volume of paracentesis & \multirow{2}{*}{67} & \multirow{2}{*}{67} \\
\hline & Cellulitis at exit site & Required oral antibiotics & & \\
\hline Patient 5 & Leak & $\begin{array}{l}\text { Required increased volume of paracente- } \\
\text { sis }\end{array}$ & 26 & 26 \\
\hline \multirow[t]{2}{*}{ Patient 6} & Leak & Required increased volume of paracentesis & \multirow{2}{*}{168} & \multirow{2}{*}{168} \\
\hline & Cellulitis at exit site & Required oral antibiotics & & \\
\hline Patient 7 & $\begin{array}{l}\text { Hypotension following drain insertion and } \\
\text { initial paracentesis }\end{array}$ & Required bolus intravenous fluids & 9 & 9 \\
\hline Patient 8 & None & & 18 & 18 \\
\hline Patient 9 & None & & 8 & 8 \\
\hline \multirow{2}{*}{ Mean } & & & \multirow{2}{*}{98.9} & 140 (after initial catheter) \\
\hline & & & & 114.5(after last catheter) \\
\hline
\end{tabular}

*Patient 3 had two catheters inserted. The second catheter was removed after 192 days due to infrequent use.

tes forcing ascitic fluid through the tunnel. These were resolved promptly by draining extra fluid from the abdomen. We have now started using a layered purse string suture at the skin puncture at the distal end of the tunnel. We have not had any further tract leaks since this minor change to our practice.

One patient accidentally displaced his catheter. It was replaced over a guidewire and a new tunnel was formed. The same patient had this second catheter removed 192 days later due to resolution of the ascites.
One catheter was blocked following infiltration of the tunnel with tumor. This catheter was removed.

\section{Catheter life/Catheter management}

The mean catheter life was 98.9 days (range 8-296 days). Four of the patients 
had all of their drainages conducted in the community. Four of the patients attended the day ward for elective drainages.

\section{Re-hospitalization post insertion}

Re-hospitalization was defined as any Emergency Department attendance or any inpatient admission. These are presented in Table 3. Three patients had no re-hospitalizations post insertion. There were a total of 14 re-hospitalizations in the group. Five of these were directly attributable to ascites or the presence of the catheter. The average number of rehospitalizations due to catheter/ascites was 0.55 . The mean number of total rehospitalizations was 1.55 per patient (range 0-5).

There were 2 presentations to Emergency Department with symptomatic ascites post insertion. These were managed in the Emergency Department with an extra drainage and avoided inpatient admission.

One patient was admitted for removal of his catheter due to blockage caused by infiltration with tumor. One patient was admitted for reinsertion of his catheter following accidental displacement by the patient. The same patient had this second tube removed 192 days later due to resolution of the ascites.

\section{Place of death}

Place of death was at home for 8 of the 9 patients $(88.8 \%)$. One of the patients deteriorated due to renal failure/disease in hospital and died 8 days after catheter insertion without ever achieving discharge.

\section{Discussion}

We report a series of patients with malignant ascites who were managed with tunneled peritoneal catheter placement. There is no current consensus on the best management strategy.

Diuretic therapy such as furosemide and spironolactone are commonly used but reported response rates are poor $[1,8]$. Nevertheless they provide a minimally invasive option and can go for trial on an individual basis.
Invasive strategies include peritoneo-gastric shunts, peritoneo-urinary shunts, peritoneo-venous shunts, repeated paracentesis and peritoneal catheter placement. Peritoneo-gastric and peritoneo-urinary shunts are of limited use and prone to mechanical difficulties [9-11].

Peritoneo-venous shunts, whereby ascitic fluid is drained from the peritoneal cavity into a central vein, have been used for a long time for this indication $[12,13]$. However, general application of this technique is limited due to contraindications and complications [14]. One of the advantages of this technique is the return of a protein rich fluid to the intravascular compartment [12]. A recent review reported complication rates of up to $38 \%$ with $24 \%$ occlusion rate [15]. A newer technique involving an externalized portovenous shunt was also recently described in a small group of patients with apparent success [16]. Larger studies are needed to assess this technique.

Repeated paracenteses is the most

Table 3. Number and reasons for rehospitalisation and plan for catheter management post insertion of the peritoneal catheter.

\begin{tabular}{llll}
\hline & Setting of Ongoing Paracentesis via Indwelling Catheter & Rehospitalisations & Reason for Admission/ Attendance \\
\hline Patient 1 & Home (Home care team) & 3 & Recurrent pleural effusions, pleurodesis, VATS \\
\hline Patient 2 & Oncology Day Ward & 3 & $\begin{array}{l}\text { Pulmonary oedema, dyspnoea, hyponatraemia } \\
\text { Catheter blocked by tract infiltration }\end{array}$ \\
\hline Patient 3 & Home (Home care team) & 6 & $\begin{array}{l}\text { Recurrent subacute bowel obstruction, delirium, fracture of neck of femur } \\
\text { Accidental catheter displacement }\end{array}$ \\
\hline Patient 4 & Home (self-managed) \& Day Ward & 0 & Abdominal distension \\
\hline Patient 5 & Home (managed by family) \& Day Ward & 1 & Abdominal distension \\
\hline Patient 6 & Oncology Day Ward & 1 & \\
\hline Patient 7 & Home (managed by family \& home care team) & 0 & \\
\hline Patient 8 & Home (managed by family) & 0 & $\mathrm{n} / \mathrm{a}^{*}$ \\
\hline Patient 9 & Oncology Day Ward & & \\
\hline
\end{tabular}

*Patient 9 did not achieve discharge following catheter insertion and died as an in-patient. 
widely practiced therapeutic option for malignant ascites. Its advantages are that it is easily and quickly performed with standard equipment under local anesthesia and there are a large number of hospital doctors competent in this technique. In a prospective study of paracentesis in the palliative population there was a statistically significant improvement in symptoms at 72 hours post paracentesis [17]. Complications including intestinal injury, hemoperitoneum, and peritonitis are rare $[18,19]$. In one series of 179 patients, four had hemorrhagic complications requiring hospital admission and blood transfusion [19]. This however is a costly technique usually requiring repeated hospital admission for management. Patients typically present to the Emergency Department in a crisis.

Non-tunneled peritoneal catheters have been used with varying degrees of success. Lee et al. have reported a series of 45 non-tunneled catheters in 38 patients over a four year period [20]. There were two catheter related deaths attributed to fatal hypotension within 24 hours of insertion and there was a high rate of catheter related sepsis (13/30 patients). Sartori et al. reported on the placement of 21 catheters in 21 patients and obtained a low complication rate [21].

Tunneled peritoneal catheter placement has been widely reported for the palliation of malignant ascites in patients with an expected life expectancy of months [2-5,14,22-24]. There are no prospective trials directly comparing the two main brands of catheter Tenckhoff and Pleurx.

Rosenberg et al. report on a retrospective review of patients with malignant ascites managed with repeated paracentesis (392 procedures in 67 patients) versus those managed with Pleurx catheters (40 patients) [5]. The overall complication rate was similar between the groups.

Our data presented above show our institutions experience with tunneled Tenckhoff catheters. Overall it was a successful technique with no procedure related deaths or major complications. There were several minor complications. Most occurred early in the catheter life. Clearly patient selection is an important factor given that one of our patients began to deteriorate due to progressive renal failure shortly after catheter insertion and died in hospital. Tapping et al. looked at prognostic factors for catheter survival and found that renal failure was predictive of short catheter life [24].

The readmission rate for catheter/ ascitic issues was low. There were three catheter related readmissions and two attendances at ED requiring extra drainage for symptomatic ascites.

One of the shortfalls highlighted in this study is the failure to manage the catheter entirely in the community in that some patients came to the oncology day ward on an elective basis for their drainages. Some of this can be accounted for due to a learning curve with community palliative care team in relation to this new management strategy. The catheter management ideally could have been done entirely in the community with better education and support of the family and palliative home care team.

One of the successes of this technique is the ability of the patient to control his own symptoms and alert the team if more frequent drainage is re- quired without waiting until symptoms are unbearable and coming to the ED. We also felt that this management strategy probably contributed to enabling these patients to achieve death at home rather than in hospital.

This is a safe and effective technique with low complication rates for the management of palliative patients with malignant ascites. It may provide a more acceptable management strategy for the patient who has a short life expectancy and symptomatic malignant ascites. Education of the patient and their carer is a key factor for success.

\section{Conflict of interest}

The authors declare no conflict of interest.

\section{References}

1. Mackey JR, Venner PM. Malignant ascites: demographics, therapeutic efficacy and predictors of survival. Can $\mathrm{J}$ Oncol 1996;6:474-80.

2. Brooks RA, Herzog TJ. Long-term semi-permanent catheter use for the palliation of malignant ascites. Gynecol Oncol 2006;101 (2):360-2.

3. O'Neill MJ, Weissleder R, Gervais DA, Hahn PF, Mueller PR. Tunnelled peritoneal catheter placement under sonographic and fluoroscopic guidance in the palliative treatment of malignant ascites. Am J Roentgenol 2001;177:615-8.

4. Barnett TD, Rublins J. Placement of a permanent tunnelled peritoneal drainage catheter for palliation of malignant ascites: a simplified percutaneous approach. J Vasc Interv Radiol 2002;13:379-83.

5. Rosenberg S, Courtney A, Nemcek AA, Omary RA. Comparison of percutaneous management techniques for recurrent malignant ascites. J Vasc Interv Radiol 2004;15:1129-31.

6. Fleming ND, Alvarez-Secord A, Von Gruenigen V, Miller MJ, Abernethy AP. 
Indwelling catheters for the management of refractory malignant ascites: a systematic literature overview and retrospective chart review. J Pain Symptom Manage 2009;38 (3):341-9.

7. Keen A, Fitzgerald D, Bryant A, Dickinson HO. Management of drainage for malignant ascites in gynaecological cancer. Cochrane Database of Systematic Reviews 2010, Issue 1. Art. No.: CD007794. DOI: 10.1002/14651858. CD007794.pub2.

8. Pockros PJ, Esrason KT, Nguyen C, Duque J, Wood S. Mobilisation of malignant ascites with diuretics is dependent on ascitic fluid characteristics. Gastroenterology 1992;103:1302-6.

9. Lorentzen T, Sengeløv L, Nolsøe CP, Khattar SC, Karstrup S, von der Maase H. Ultrasonically guided insertion of a peritoneo-gastric shunt in patients with malignant ascites. Acta Radiol 1995;36(5):481-4.

10. Stehman FB, Ehrlich CE. Peritoneocystic shunt for malignant ascites. Gynecol Oncol 1984;18(3):402-7.

11. Rozenblit GN, Del Guercio LR, Rundback JH, Poplausky MR, Lebovics E. Peritoneal-urinary drainage for treatment of refractory ascites: a pilot study. J Vasc Interv Radiol 1998;9(6):9981005.
12. Hussain FF, Meer ZF, Lopez AJ. Peritoneovenous shunt insertion for intractable ascites: a district general hospital experience. Cardiovasc Interv Radiol 2004;27;325-8.

13. Mamada Y, Yoshida H, Taniai N, Bandou K, Shimizu T, Kakinuma D, et al. Peritoneovenous shunts for palliation of malignant ascites. J Nippon Med Sch 2007;74(5):355-8.

14. Mullard AP, Bishop JM, Jibani M. Intractable malignant ascites: an alternative management option. J Palliat Med 2001;14 (2):251-3.

15. White MA, Agle SC, Padia RK, Zervos EE. Denver peritoneovenous shunts for the management of malignant ascites: a review of the literature in the post LeVeen Era. Am Surg 2011;77(8):10705.

16. Tokue H, Takeuchi Y, Arai Y, Sofue K, Sakamoto N, Tsushima Y, et al. Feasibility of externalized peritoneovenous shunt (EPVS) for malignant ascites. World J Surg Oncol 2011;9:82.

17. McNamara P. Paracentesis - an effective method of symptom control in the palliative care setting? Palliat Med 2000;14:62-4.

18. Runyon BA. Paracentesis of ascitic fluid: a safe procedure. Arch Intern Med 1986;146:2259-61.
19. Webster ST, Brown KL, Lucey MR, Nostrant TT. Hemorrhagic complications of large volume abdominal paracentesis . Am J Gastrenterol 1996;92:366-8.

20. Lee A, Lau TN, Yeong KY. Indwelling catheters for the management of malignant ascites. Support Care Cancer 2000;8:493-9.

21. Sartori S, Nielsen I, Trevisani L, Tassinari D, Ceccotti P, Barillani M, et al. Am J Roentgenol 2002;179:1618-20.

22. Belfort MA, Stephens PJ, DeHaek K, Soeters R, Krige JE. A new approach to the management of malignant ascites: a permanently implanted abdominal drain. Eur J Surg Oncol 1990;16(1):4753.

23. Courtney A, Nemcek AA, Rosenberg S, Tutton S, Darcy M, Gordon G. Prospective evaluation of the PleurX Catheter when used to treat recurrent ascites associated with malignancy. J Vasc Interv Radiol 2008;19 (2):1723-31.

24. Tapping CR, Ling L, Razack A. PleurX drain use in the management of malignant ascites: safety, complications, long-term patency and factors predictive of success. Br J Radiol 2011;85(1013):623-8.

\section{.COCHRANE UPDATES \& NICE GUIDELINES .}

\section{ANTENATAL CARE}

This quality standard defines clinical best practice within this topic area. It provides specific, concise quality statements, measures and audience descriptors to provide the public, health and social care professionals, commissioners and service providers with definitions of high-quality care.

This quality standard covers the antenatal care of all pregnant women up to 42 weeks of pregnancy, in all settings that provide routine antenatal care, including primary, community and hospital-based care. The quality standard addresses routine antenatal care, including screening tests for complications of pregnancy, but it does not address the additional care needed to manage these complications if they arise in pregnancy (for example, gestational diabetes, pre-eclampsia and venous thromboembolism).

(Source: NICE Quality Standards, QS22, September 2012; available at http://guidance.nice.org.uk/QS22) 